the same time [fig. S5A (19)] are consistent with extracellular signals.

After a relatively brief $(\sim 40-\mathrm{s})$ period of extracellular signals, we observed several pronounced changes in recorded signals (Fig. 4, B and C, II and III) without application of external force to the PDMS/cell support. Specifically, the initial extracellular signals gradually disappeared (Fig. 4, B and C, II, pink stars). There was a concomitant decrease in baseline potential, and new peaks emerged that had an opposite sign, similar frequency, much greater amplitude, and longer duration (Fig. 4B, II, green stars). These new peaks, which are coincident with cardiomyocyte cell beating, rapidly reached a steady state (Fig. 4B, III) with an average calibrated peak amplitude of $\sim 80 \mathrm{mV}$ and duration of $\sim 200 \mathrm{~ms}$. The amplitude, sign, and duration are near those reported for whole-cell patch clamp recordings from cardiomyocytes $(27,28)$; thus, we conclude that these data represent a transition to steadystate intracellular recording (Fig. 4A, right) with the $3 \mathrm{D}$ nanowire probe.

Detailed analysis of the latter steady-state peaks (Fig. 4C, III) shows five characteristic phases of a cardiac intracellular potential $(27,28)$, including (a) resting state, (b) rapid depolarization, (c) plateau, (d) rapid repolarization, and (e) hyperpolarization. In addition, a sharp transient peak (blue star) and the notch (orange star) possibly associated with the inward sodium and outward potassium currents (28) can be resolved. Optical images recorded at the same time as these intracellular peaks (fig. S5B) showed the kinked nanowire probe tips in a possible intracellular region of the cell (19). When the PDMS/cell substrate was mechanically retracted from the $3 \mathrm{D}$ kinked nanowire devices, the intracellular peaks disappeared, but they reappeared when the cell substrate was brought back into gentle contact with the device. This process could be repeated multiple times without degradation in the recorded signal. When vertical 3D nanoprobe devices were bent into a configuration with angle $\theta<\sim 50^{\circ}$ with respect to the substrate, or when kinked nanowire devices were fabricated on planar substrates, we could record only extracellular signals. These results confirm that electrical recording arises from the highly localized, pointlike nanoFET near the probe tip, which (i) initially records only extracellular potential, (ii) simultaneously records both extracellular and intracellular signals as the nanoFET spans the cell membrane, and (iii) records only intracellular signals when fully inside the cell.

Additional work remains to develop this new synthetic nanoprobe as a routine tool like the patch-clamp micropipette $(10,11)$, although we believe that there are already clear advantages: Electrical recording with kinked nanowire probes is relatively simple without the need for resistance or capacitance compensation $(9,11)$; the nanoprobes are chemically less invasive than pipettes, as there is no solution exchange; the small size and biomimetic coating minimizes me- chanical invasiveness; and the nanoFETs have high spatial and temporal resolution for recording.

\section{References and Notes}

1. D. A. Giljohann, C. A. Mirkin, Nature 462, 461 (2009)

2. T. Cohen-Karni, B. P. Timko, L. E. Weiss, C. M. Lieber, Proc. Natl. Acad. Sci. U.S.A. 106, 7309 (2009).

3. J. F. Eschermann et al., Appl. Phys. Lett. 95, 083703 (2009).

4. Q. Qing et al., Proc. Natl. Acad. Sci. U.S.A. 107, 1882 (2010).

5. I. Heller, W. T. T. Smaal, S. G. Lemay, C. Dekker, Small 5, 2528 (2009).

6. W. Lu, C. M. Lieber, Nat. Mater. 6, 841 (2007).

7. A. Grinvald, R. Hildesheim, Nat. Rev. Neurosci. 5, 874 (2004).

8. M. Scanziani, M. Häusser, Nature 461, 930 (2009).

9. R. D. Purves, Microelectrode Methods for Intracellular Recording and lonophoresis (Academic Press, London, 1981).

10. B. Sakmann, E. Neher, Annu. Rev. Physiol. 46, 455 (1984).

11. A. Molleman, Patch Clamping: An Introductory Guide to Patch Clamp Electrophysiology (Wiley, Chichester, UK, 2003).

12. R. M. Wightman, Science 311, 1570 (2006).

13. A. G. Ewing, T. G. Strein, Y. Y. Lau, Acc. Chem. Res. 25, 440 (1992)

14. M. G. Schrlau, N. J. Dun, H. H. Bau, ACS Nano 3, 563 (2009).

15. J. P. Donoghue, Nat. Neurosci. 5 (suppl.), 1085 (2002).

16. M. leong, B. Doris, J. Kedzierski, K. Rim, M. Yang, Science 306, 2057 (2004).

17. M. Ferrari, Nat. Rev. Cancer 5, 161 (2005).
18. B. Z. Tian, P. Xie, T. J. Kempa, D. C. Bell, C. M. Lieber, Nat. Nanotechnol. 4, 824 (2009).

19. Materials and methods are available as supporting material on Science Online.

20. C. Conde, A. Cáceres, Nat. Rev. Neurosci. 10, 319 (2009).

21. T. G. Leong et al., Proc. Natl. Acad. Sci. U.S.A. 106, 703 (2009)

22. N. Misra et al., Proc. Natl. Acad. Sci. U.S.A. 106, 13780 (2009).

23. X. J. Zhou, J. M. Moran-Mirabal, H. G. Craighead P. L. McEuen, Nat. Nanotechnol. 2, 185 (2007).

24. L. V. Chernomordik, M. M. Kozlov, Nat. Struct. Mol. Biol. 15, 675 (2008)

25. W. C. Claycomb et al., Proc. Natl. Acad. Sci. U.S.A. 95, 2979 (1998).

26. B. D. Almquist, N. A. Melosh, Proc. Natl. Acad. Sci. U.S.A. 107, 5815 (2010).

27. D. M. Bers, Nature 415, 198 (2002).

28. D. P. Zipes, ]. Jalife, Cardiac Electrophysiology: From Cell to Bedside (Saunders, Philadelphia, ed. 2, 2009).

29. We thank G. Yellen, W. C. Claycomb, B. P. Bean P. T. Ellinor, G. H. Yu, D. Casanova, B. P. Timko, and T. Dvir for help with experiments and data analysis. C.M.L. acknowledges support from a NIH Director's Pioneer Award (5DP10D003900), a National Security Science and Engineering Faculty Fellow (NSSEFF) award (N00244-09-10078), and the McKnight Foundation Neuroscience award.

Supporting Online Material

www.sciencemag.org/cgi/content/full/329/5993/830/DC1 Materials and Methods

Figs. S1 to S5

References

10 May 2010; accepted 7 July 2010

10.1126/science.1192033

\title{
Terrestrial Gross Carbon Dioxide Uptake: Global Distribution and Covariation with Climate
}

Christian Beer, ${ }^{1 *}$ Markus Reichstein, ${ }^{1}$ Enrico Tomelleri, ${ }^{1}$ Philippe Ciais, ${ }^{2}$ Martin Jung, $^{1}$ Nuno Carvalhais, ${ }^{1,3}$ Christian Rödenbeck, ${ }^{4}$ M. Altaf Arain, ${ }^{5}$ Dennis Baldocchi, ${ }^{6}$ Gordon B. Bonan, ${ }^{7}$ Alberte Bondeau, ${ }^{8}$ Alessandro Cescatti, ${ }^{9}$ Gitta Lasslop, ${ }^{1}$ Anders Lindroth, ${ }^{10}$ Mark Lomas, ${ }^{11}$ Sebastiaan Luyssaert, ${ }^{12}$ Hank Margolis, ${ }^{13}$ Keith W. Oleson, ${ }^{7}$ Olivier Roupsard, ${ }^{14,15}$ Elmar Veenendaal, ${ }^{16}$ Nicolas Viovy, ${ }^{2}$ Christopher Williams, ${ }^{17}$ F. Ian Woodward, ${ }^{11}$ Dario Papale ${ }^{18}$

Terrestrial gross primary production (GPP) is the largest global $\mathrm{CO}_{2}$ flux driving several ecosystem functions. We provide an observation-based estimate of this flux at $123 \pm 8$ petagrams of carbon per year $\left(\mathrm{Pg} \mathrm{C}\right.$ year $\left.^{-1}\right)$ using eddy covariance flux data and various diagnostic models. Tropical forests and savannahs account for $60 \%$. GPP over $40 \%$ of the vegetated land is associated with precipitation. State-of-the-art process-oriented biosphere models used for climate predictions exhibit a large between-model variation of GPP's latitudinal patterns and show higher spatial correlations between GPP and precipitation, suggesting the existence of missing processes or feedback mechanisms which attenuate the vegetation response to climate. Our estimates of spatially distributed GPP and its covariation with climate can help improve coupled climate-carbon cycle process models.

$\mathrm{T}$ errestrial plants fix carbon dioxide $\left(\mathrm{CO}_{2}\right)$ as organic compounds through photosynthesis, a carbon (C) flux also known at the ecosystem level as gross primary production (GPP). Terrestrial GPP is the largest global carbon flux, and it drives several ecosystem functions, such as respiration and growth. GPP thus contributes to human welfare because it is the basis for food, fiber, and wood production. In addition, GPP, along with respiration, is one of the major processes controlling land-atmosphere $\mathrm{CO}_{2}$ exchange, providing the capacity of terrestrial ecosystems to partly offset anthropogenic $\mathrm{CO}_{2}$ emissions.

Although photosynthesis at the leaf and canopy level are quite well understood, only tentative observation-based estimates of global terrestrial GPP have been possible so far. Plant- and standlevel GPP has previously been calculated as two times biomass production $(1,2)$, with substantial 
variation between biomes and sites (3-5). In the absence of direct observations, a combined GPP of all terrestrial ecosystems of $120 \mathrm{Pg} \mathrm{C}$ year $^{-1}$ was obtained ( 6 ) by doubling global biomass production estimates (7) without an empirical basis of spatially resolved biomass production and its relationship to GPP. A global terrestrial GPP of 100 to $150 \mathrm{Pg} \mathrm{C}$ year $^{-1}$ is consistent with the observed variation of ${ }^{18} \mathrm{OCO}$ in the atmosphere $(8,9)$. However, the ability of ${ }^{18}$ OCO to constrain GPP de-

${ }^{1}$ Biogeochemical Model-Data Integration Group, Max Planck Institute for Biogeochemistry, 07745 Jena, Germany. 'Laboratoire des Sciences du Climat et de L'Environnement, Institut Pierre Simon Laplace, CEA-CNRS-UVSQ, Gif-sur-Yvette, France. ${ }^{3}$ Faculdade de Ciências e Tecnologia (FCT), Universidade Nova de Lisboa, Caparica, Portugal. ${ }^{4}$ Biogeochemical Systems, Max Planck Institute for Biogeochemistry, 07745 Jena, Germany. ${ }^{5}$ McMaster Centre for Climate Change, McMaster University, Hamilton, Ontario, Canada. ${ }^{6}$ Department of Environmental Science, Policy and Management and Berkeley Atmospheric Science Center, University of California, Berkeley, CA 94720, USA. ${ }^{7}$ National Center for Atmospheric Research, Boulder, CO 80305, USA. ${ }^{8}$ Potsdam Institute for Climate Impact Research (PIK), 14473 Potsdam, Germany. ${ }^{9}$ Climate Change Unit, Institute for Environment and Sustainability, European Commission, DG Joint Research Centre, Ispra, Italy. ${ }^{10}$ Department of Earth and Ecosystem Science, Lund University, Sweden. ${ }^{11}$ Department of Animal and Plant Sciences, University of Sheffield, Sheffield S10 2TN, UK. ${ }^{12}$ Departement Biologie, Universiteit Antwerpen, Belgium. ${ }^{13}$ Centre d'étude de la forêt, Faculté de foresterie, de géographie et de géomatique, Université Laval, Quebec, Canada. ${ }^{14}$ Cirad-Persyst, UPR80 Fonctionnement et Pilotage des Ecosystémes de Plantation, Montpellier, France. ${ }^{15}$ CATIE (Centro Agronómico Tropical de Investigación y Enseñanza), Turrialba, Costa Rica. ${ }^{16}$ Nature Conservation and Plant Ecology Group, Wageningen University, Netherlands. ${ }^{17}$ Graduate School of Geography, Clark University, Worcester, MA 01610, USA. ${ }^{18}$ Department of Forest Environment and Resources, University of Tuscia, Viterbo, Italy.

*To whom correspondence should be addressed. E-mail: christian.beer@bgc-jena.mpg.de pends critically on the isotopic imbalance between GPP and respiration, and large uncertainties remain associated with isotope fractionation processes (10). The coupled uptake of carbonyl sulfide and $\mathrm{CO}_{2}$ by plants $(11,12)$ could potentially be used to further constrain terrestrial GPP by the combination of atmospheric [COS] measurements with an inversion of the atmospheric transport (13) once the ratio of $\mathrm{CO}_{2}$ versus $\mathrm{COS}$ uptake, the additional COS deposition to soils, and the COS efflux from oceans is more precisely quantified.

As an alternative to directly constraining atmospheric data to estimate GPP, local information can be built into a process-oriented biosphere model, which is then applied globally. Knowledge of radiative transfer within vegetation canopies and of leaf photosynthesis has been used to represent GPP within process-oriented biosphere models, which explicitly simulate the behavior of the ecosystem as an interaction of the system components (e.g., leafs, roots, and soil) in a reductionist or mechanistic way. If these models are designed to also simulate a changing state of the biosphere (e.g., leaf area index and carbon pools), predictions of ecosystem dynamics under changing environmental conditions can be attempted (14). However, these process-oriented models are complex combinations of scientific hypotheses; hence, their results depend on these embedded hypotheses. A complementary approach is data-oriented or diagnostic modeling where general relationships between existing data sets are first inferred at site-level and then applied globally by using global grids of explanatory variables. Particularly when dataadaptive machine learning approaches are employed (e.g., artificial neural networks), results are much less contingent on theoretical assumptions and can be considered as data benchmarks for process models. However, being essentially a statistical approach, the diagnostic models do lack the capacity of extrapolating to completely different conditions and hinge on the availability of sufficient data. With the advent of a global network of ecosystem-level observations of $\mathrm{CO}_{2}$ biosphereatmosphere exchange (15) (www.fluxdata.org) and the development of new diagnostic modeling approaches, a data-oriented global estimation of GPP has become feasible. In this study, we estimate terrestrial GPP and its spatial details by diagnostic models and compare spatial correlations with climate variables to results from process-oriented models.

The diagnostic modeling comprises two steps, the parametrization of GPP in relation to explanatory variables at sites and the application of the model by using gridded information about these explanatory variables. For the first step, GPP was estimated by partitioning continuous measurements of net ecosystem exchange (NEE) into GPP and ecosystem respiration at flux tower sites (16). Two flux partitioning methods were considered using night-time or day-time NEE (16). Such site-level GPP data was then used to calibrate five highly diverse diagnostic models, which relate GPP to meteorology, vegetation type, or remote sensing indices at daily, monthly, or annual time scales (16). Two of these approaches are machine learning techniques: a model tree ensemble (MTE) (17) and an artificial neural network (ANN) (18). The Köppen-Geiger cross Biome (KGB) approach is a look-up table of mean GPP per ecoregion. GPP of whole river catchment areas is estimated by the water use efficiency approach (WUE) $(19,20)$,

Fig. 1. (A) Distributions of global GPP (Pg C year $\left.{ }^{-1}\right)$ for the five data-driven approaches that are most constrained by data, their combined global GPP distribution, and the GPP distribution by the Miami model. Shown are the median (red horizontal lines), the quartiles (blue boxes), and the 2.5 and 97.5 percentiles (vertical black lines), indicating the $95 \%$ confidence interval. MTE is

A

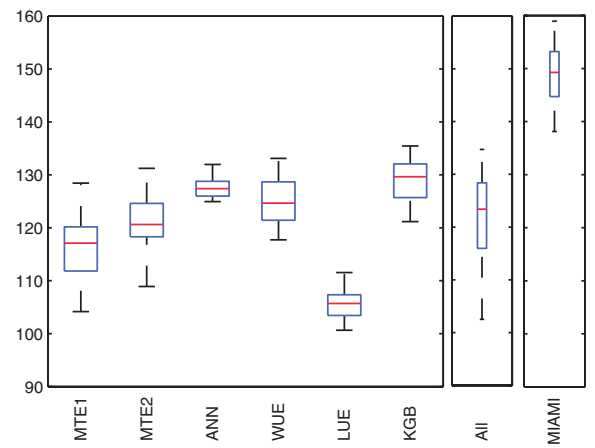

B

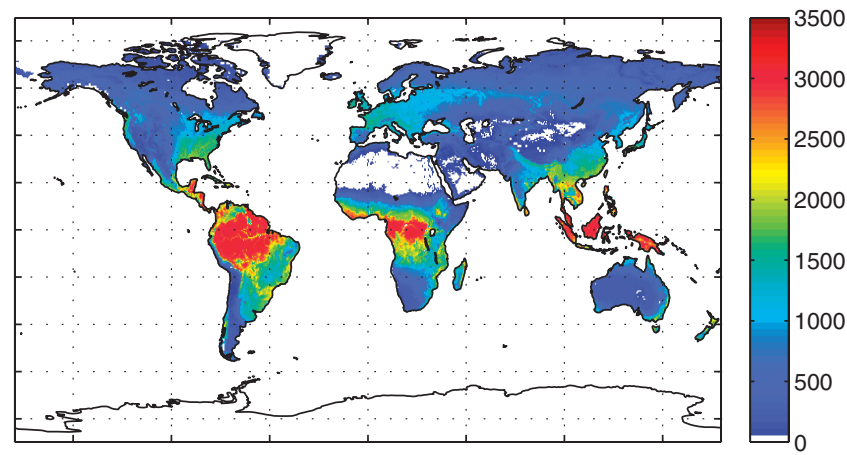

C

either driven by fAPAR only (MTE1) or by both fAPAR and climate data (MTE2) (16). (B) Spatial details of the median annual GPP $\left(\mathrm{gC} / \mathrm{m}^{2} / \mathrm{a}\right)$ from the spatially explicit approaches MTE1, MTE2, ANN, LUE, and KGB. (C) Latitudinal pattern ( $0.5^{\circ}$ bands) of annual GPP. The gray area represents the range of the diagnostic models MTE1, MTE2, ANN, LUE, and KGB. The red area represents the range of process model results (LPJ-DGVM, LPJmL, ORCHIDEE, CLM-CN, and SDGVM). The thick lines represent the medians of both ranges. The dashed black line shows the result for northern extratropical regions from an independent diagnostic model. In this approach, we combined gridded information about the seasonal NEE amplitude based on atmospheric $\mathrm{CO}_{2}$ data and an inversion of atmospheric $\mathrm{CO}_{2}$ transport with empirical relationships between annual GPP and the seasonal amplitude of NEE derived at flux tower sites.

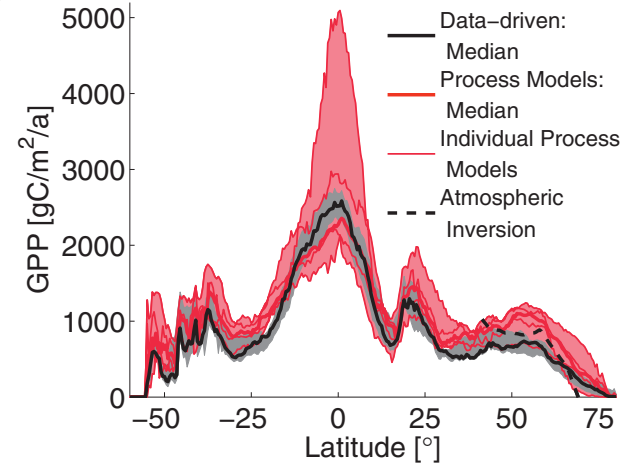


which combines recently derived global WUE fields with the long-term averaged evapotranspiration at the watershed scale. This is an important constraint at the global scale, but the spatial resolution is too coarse to use the WUE approach for estimating the spatial distribution of GPP. The light-use efficiency approach (LUE) $(21,22)$ was applied by combining in situ Bayesian calibration with an uncertainty propagation per vegetation and climate class. The Miami model (23) simply exploits the empirically obtained dependence of photosynthesis on temperature and precipitation. The second step, the mapping of flux tower GPP to the land surface, was performed by applying these diagnostic models to fields of remote sensing (24-26) and climatic data (27-29), which are now available with improved accuracy and high spa- tial resolution. In so doing, we take into account several sources of uncertainty, including uncertainty from model parametrization and from explanatory variables (16).

By making use of the new data streams and the ensemble of five diagnostic models, we present an observation-based estimate of an average global terrestrial GPP of $123 \mathrm{Pg} \mathrm{C}_{\text {year }}{ }^{-1}$ during the period 1998 to 2005 (Fig. 1A). Uncertainties and preprocessing of tower $\mathrm{CO}_{2}$ flux measurements, tower representativeness, flux partitioning into GPP, uncertainties of climate and remote sensing data sets, and structural uncertainties of the diagnostic models propagate to a global uncertainty with a $95 \%$ confidence range from 102 to $135 \mathrm{Pg} \mathrm{C}$ year ${ }^{-1}$ or a robust estimate of standard deviation (30) of $8 \mathrm{Pg} \mathrm{C}$ year ${ }^{-1}$. Results from the

Table 1. GPP for biomes of the world as defined by Prentice et al. (6). Combining the biome extent (fig. S17) with the spatially explicit GPP distributions by the approaches MTE1, MTE2, ANN, LUE, WUE, and KGB led to the respective median GPP per unit area separately for each biome (fig. S4). These medians were then multiplied by the biome area $(6,7)$ (fig. S4) to estimate GPP in column 2 . The estimated GPP total of $122 \mathrm{Pg} \mathrm{C}$ year ${ }^{-1}$ does not equal our overall median of $123 \mathrm{Pg} \mathrm{C}_{\text {year }}{ }^{-1}$ because the biome area defined by fig. S17 and by (6) differ slightly. The third column shows GPP as estimated by using NPP numbers from Saugier et al. (7) under the assumption that NPP/GPP $=0.5$ (6).

\begin{tabular}{lcc} 
Biome & $\begin{array}{c}\text { GPP } \\
(\text { Pg C year }\end{array}$ & $\begin{array}{c}\text { GPP } \\
\text { (Pg C } \text { year }^{-1} \text { ) }\end{array}$ \\
\hline Tropical forests & 40.8 & 43.8 \\
Temperate forests & 9.9 & 16.2 \\
Boreal forests & 8.3 & 5.2 \\
Tropical savannahs and grasslands & 31.3 & 29.8 \\
Temperate grasslands and shrublands & 8.5 & 14 \\
Deserts & 6.4 & 7 \\
Tundra & 1.6 & 1 \\
Croplands & 14.8 & 8.2 \\
Total & 121.7 & 125.2 \\
\hline
\end{tabular}

*Based on integrated numbers for biomes $(6,7)$

LUE approach were higher when using National Centers for Environmental Prediction (NCEP) radiation. However, we do not show NCEP-driven results because NCEP radiation and precipitation is known to be biased $(31,32)$. The Miami model overestimates GPP compared to other approaches, particularly in sparsely vegetated areas with strong seasonality, such as savannahs, shrublands, and tundra (16) (table S5), because it does not account for the effect of climate-independent changes in vegetation structure (e.g., degradation) and vegetation type on GPP. Indeed, residuals of this model correlate significantly with mean annual fraction of absorbed photosynthetically active radiation (fAPAR) from remote sensing (fig. S14). Hence, being a classic model, it is shown only for comparison, but results from the Miami model were not taken into account in the following analyses.

Tropical forests assimilate $34 \%$ of the global terrestrial GPP (Table 1) and have the highest GPP per unit area (table S5). Savannahs account for $26 \%$ of the global GPP and are the second most important biome in terms of global GPP. The large area of savannahs (about twice the surface area of tropical forests) explain their high contribution. Moreover, the results highlight the importance of taking into account $\mathrm{C} 4$ vegetation in global GPP estimates. Based on the C4 distribution (figs. S6 and S7), more than $20 \%$ of terrestrial GPP is conducted by $\mathrm{C} 4$ vegetation. Given that there were less than 20 site-years of flux data for C4-dominated ecosystems, our uncertainty is largest for this type of vegetation. Therefore, an expansion of observational networks should focus on tropical C4 ecosystems. Boreal forests show a clear longitudinal gradient in GPP in northern Eurasia where GPP in the boreal zone decreases toward the east, where
Fig. 2. Partial correlation in the spatial domain between GPP from Fig. 1B and either (A) CRU precipitation, (B) CRU air temperature, or (C) ECMWF ERA-Interim short-wave radiation after applying a moving $4.5^{\circ}$ by $4.5^{\circ}$ spatial window and subsequent median filtering. Shown are significant correla-

A

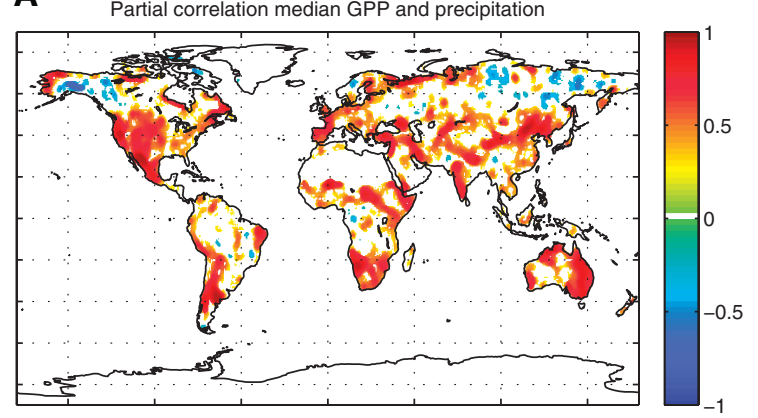

tions $(P<0.01)$ of which the correlation coefficient is higher/lower than \pm 0.2 .
B

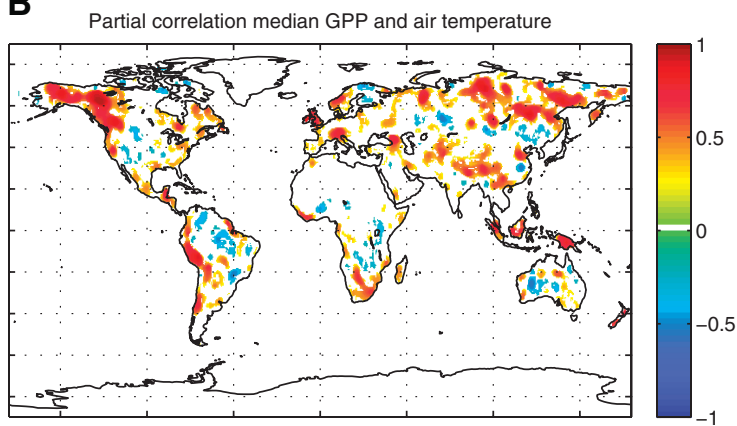

C

Partial correlation median GPP and short-wave radiation

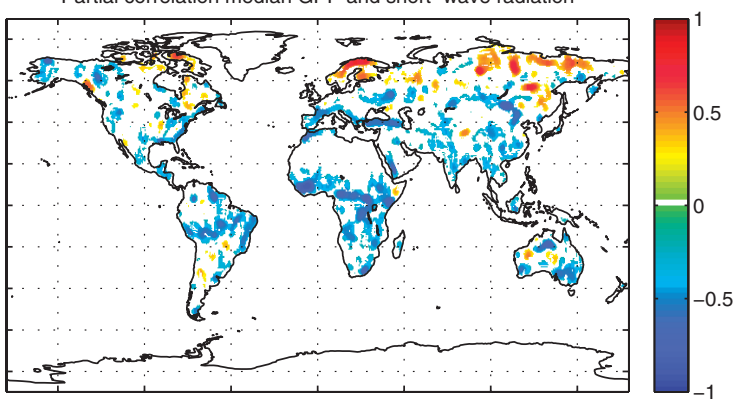


photosynthesis is subject to an increasingly continental climate (Fig. 1B).

The latitudinal pattern derived by the different diagnostic models falls into a quite narrow range (Fig. 1C). In contrast, there is a larger range among an ensemble of five process-oriented biosphere models (Fig. 1C); in comparison to our data-oriented range, some consistently overestimate GPP, and others underestimate tropical GPP while matching or slightly overestimating GPP in the temperate zone (fig. S26). A standard global parametrization of the process-oriented models has been applied in this study; it was not optimized against flux tower GPP because we aimed at evaluating the processbased GPP fields and their correlations to climatic variables. For comparison, we show results by an additional, completely different approach of scaling GPP from flux tower sites to the regional scale (fig. S16), where a reationship between the seasonal NEE amplitude and annual GPP is derived at flux tower sites and applied to the seasonal NEE amplitude derived through atmospheric inversion [update of (33)]. This approach leads to values at the upper end of the range of the diagnostic bottom-up approaches in northern extratropical regions but is still at the lower end of the range estimated by the process-oriented models. The differences between process-oriented and data-oriented estimates could lie in human-induced degradation of GPP by land use (34). However, other reasons are possible, including insufficient model parametrization or structural model errors that lead to an overestimation of GPP.

Partial correlation analyses between GPP and climatic variables for $4.5^{\circ}$ by $4.5^{\circ}$ moving windows show that spatial variation of GPP is associated with precipitation in 50 to $70 \%$ of the area of nontundra herbaceous ecosystems (Fig. $2 \mathrm{~A}$ and Table 2). Also, $50 \%$ of the crop production occurs in regions where photosynthesis is colimited by precipitation, stressing the importance of water availability for food security. Interestingly, GPP in the same proportion of temperate forest areas correlates positively with precipitation (Table 2). In contrast, the spatial GPP variability in only $30 \%$ of tropical and boreal forests seems to be associated positively with precipitation, but GPP of more than half of the boreal forests correlates positively with air temperature (Table 2). Therefore, the GPP of these biomes seems to be robust against a moderate climate variation in the order of magnitude of the current spatial variability of climate, given the very low probability of a decrease in air temperature in the boreal zone.

We find negative correlations of productivity with incoming short-wave radiation, in particular in savannahs, the Mediterranean, and Central Asian grasslands (Fig. 2C and tables S6 to S8).

Table 2. Percentage of biome area for which GPP is climatically controlled, indicated by a median partial correlation coefficient higher than 0.2 (or 0.5 in brackets). Several climate grids (CRU, ECMWF ERAInterim, and GPCP precipitation) were used to perform a partial correlation between the median GPP map (Fig. 1B) and climate variables for $4.5^{\circ}$ by $4.5^{\circ}$ moving windows (16). Then, the fractional area with significant $(P<0.01)$ partial correlation higher than $0.2(0.5)$ was calculated.

\begin{tabular}{lllr} 
Biome & $\mathbf{P}^{*}$ controlled & T† controlled & Rf controlled \\
\hline Tropical forests & $29(12)$ & $39(26)$ & $4(1)$ \\
Temperate forests & $\mathbf{5 0}(26)$ & $41(23)$ & $6(2)$ \\
Boreal forests & $20(5)$ & $\mathbf{5 5}(31)$ & $21(7)$ \\
Tropical savannahs and grasslands & $\mathbf{5 5 ( 3 1 )}$ & $16(5)$ & $3(0)$ \\
Temperate grasslands and shrublands & $\mathbf{6 9}(41)$ & $37(18)$ & $6(1)$ \\
Deserts & $\mathbf{6 1}(37)$ & $18(6)$ & $8(2)$ \\
Tundra & $24(13)$ & $37(27)$ & $32(12)$ \\
Croplands & $\mathbf{5 1}(25)$ & $28(13)$ & $5(1)$ \\
\hline
\end{tabular}

*Precipitation †Air temperature $\quad$ Short-wave radiation

A

Fig. 3. Percentage of vegetated land surface (A) and corresponding GPP (B) that is controlled by precipitation, depending on the chosen threshold for the partial correlation coefficients that signal a control of GPP by a climate factor. The blue areas represent the range of data-driven estimates (MTE1, MTE2, ANN, LUE, and KGB) using different climate sources [CRU, ECMWF ERA-Interim, and GPCP (16)]. This is compared to the range of process-oriented model results (LPJ-DGVM, LPJmL, ORCHIDEE, CLM-CN, and SDGVM) in red. Purple shows the overlapping area. The thick lines represent the medians of both ranges. For instance, GPP of about $40 \%$ of the vegetated land surface is controlled by water availability by defining a water control of GPP as a partial correlation coefficient between GPP and precipitation higher than 0.2 .

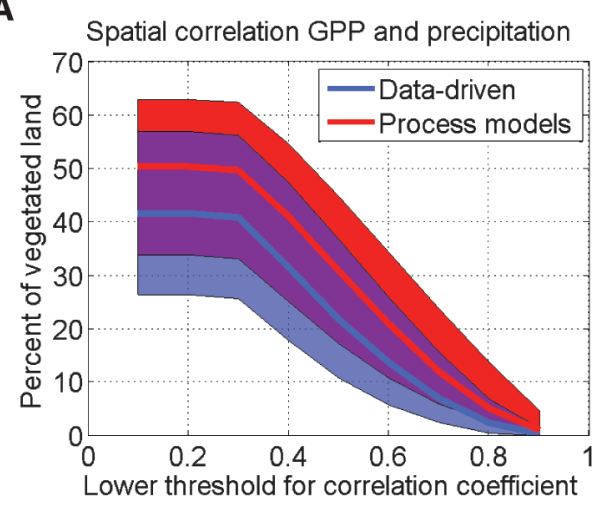

B

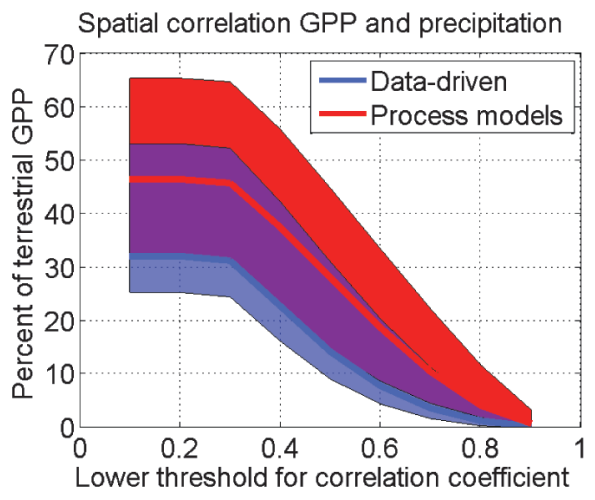

These negative partial correlations may indicate an additional indirect effect of radiation or temperature on GPP by the water balance. Both climatic variables are usually associated with higher evapotranspiration rates, which will yield more negative water balances with higher temperature or radiation levels with consequent negative effects on primary productivity in these water-limited regions. This interpretation is possible notwithstanding a direct effect of temperature on vegetation by heat stress as well as increased levels of diffuse radiation associated with overall lower levels of radiation (35).

After four decades of research on the global magnitude of primary production of terrestrial vegetation $(23,36)$, we present an observationbased estimate of global terrestrial GPP. Although we arrive at a global GPP of similar magnitude as these earlier estimates, our results add confidence and spatial details. The large range of GPP results by process-oriented biosphere models indicates the need for further constraining $\mathrm{CO}_{2}$ uptake processes in these models. Furthermore, our spatially explicit GPP results contribute to a quantification of the climatic control of GPP. Complementing theoretical or process-oriented results $(37,38)$ about climatic limitations of GPP, our observationbased results now constitute empirical evidence for a large effect of water availability on primary production over $40 \%$ of the vegetated land (Fig. 3A) and up to $70 \%$ in savannahs, shrublands, grasslands, and agricultural areas (Table 2). Our findings imply a high susceptibility of these ecosystems' productivity to projected changes of precipitation over the 21 st century (39), but a robustness of tropical and boreal forests. Results of current process models show a large range and a tendency to overestimate precipitation-associated GPP (Fig. 3B). Most likely, the association of GPP and climate in process-oriented models can be improved by including negative feedback mechanisms (e.g., adaptation) that might stabilize the systems. Our high spatial resolution GPP estimates, their uncertainty, and their relationship to climate drivers should be useful for evaluating and thus improving coupled climate-carbon cycle process models. 


\section{References and Notes}

1. E.-D. Schulze, Flora 159, 177 (1970).

2. H. Poorter, C. Remkes, H. Lambers, Plant Physiol. 94 621 (1990).

3. E. H. DeLucia, J. E. Drake, R. B. Thomas, M. Gonzalez-Meler, Glob. Change Biol. 13, 1157 (2007).

4. S. Luyssaert et al., Glob. Change Biol. 13, 2509 (2007)

5. C. M. Litton, J. W. Raich, M. G. Ryan, Glob. Change Biol. 13, 2089 (2007)

6. I. C. Prentice et al., Climate Change 2001: The Scientific Basis. Contribution of Working Group I to the Third Assessment Report of the Intergovernmental Panel on Climate Change, ]. Houghton, et al., Eds. (Cambridge University Press, Cambridge, 2001), pp. 183-237.

7. B. Saugier, J. Roy, H. A. Mooney, Terrestrial Global Productivity, ]. Roy, B. Saugier, H. A. Mooney, Eds. (Academic Press, San Diego, CA, 2001).

8. G. D. Farquhar et al., Nature 363, 439 (1993).

9. P. Ciais et al., J. Geophys. Res. 102 (D5), 5857 (1997).

10. L. Wingate et al., Proc. Natl. Acad. Sci. U.S.A. 106, 22411 (2009).

11. L. Sandoval-Soto et al., Biogeosciences 2, 125 (2005).

12. J. E. Campbell et al., Science 322, 1085 (2008).

13. P. Suntharalingam, A. ]. Kettle, S. M. Montzka, D. J. Jacob, Geophys. Res. Lett. 35, L19801 (2008).

14. P. Friedlingstein et al., J. Clim. 19, 3337 (2006).

15. D. Baldocchi, Aust. J. Bot. 56, 1 (2008).

16. Materials and methods are available as supporting material on Science Online.

17. M. Jung, M. Reichstein, A. Bondeau, Biogeosciences 6, 2001 (2009).

18. D. Papale, R. Valentini, Glob. Change Biol. 9, 525 (2003).

19. C. Beer, M. Reichstein, P. Ciais, G. D. Farquhar, D. Papale, Geophys. Res. Lett. 34, L05401 (2007).

20. C. Beer et al., Glob. Biogeochem. Cycles 23, GB2018 (2009).

21. ]. Monteith, ]. Appl. Ecol. 9, 747 (1972).

22. S. W. Running, P. Thornton, R. Nemani, J. Glassy, Methods in Ecosystem Science, O. Sala, R. Jackson, H. Mooney, R. Howarth, Eds. (Springer-Verlag, New York, 2000), pp. 44-57.

23. H. Lieth, Primary Productivity of the Biosphere, H. Lieth, R. H. Whittaker, Eds. (Springer-Verlag, Berlin, 1975), pp. 237-263
24. R. Myneni et al., Remote Sens. Environ. 83, 214 (2002).

25. N. Gobron et al., J. Geophys. Res.-Atmos. 111 (D13), D13110 (2006)

26. F. Baret et al., Remote Sens. Environ. 110, 275 (2007).

27. M. New, D. Lister, M. Hulme, I. Makin, Clim. Res. 21, 1 (2002).

28. T. D. Mitchell, P. D. Jones, Int. J. Climatol. 25, 693 (2005).

29. A. Simmons, S. Uppala, D. Dee, S. Kobayashi, ECMWF Newsletter No. 110 (European Centre for Medium-Range Weather Forecasts, Shinfield Park, Reading, UK, 2007).

30. Median absolute deviation times 1.48 .

31. B. Fekete, C. Vorosmarty, ]. Roads, C. Willmott, J. Clim. 17, 294 (2004)

32. M. Zhao, S. W. Running, R. R. Nemani, J. Geophys. Res.-Biogeosci. 111 (G1), G01002 (2006).

33. C. Rödenbeck, S. Houweling, M. Gloor, M. Heimann, Atmos. Chem. Phys. 3, 1919 (2003).

34. A. Bondeau et al., Glob. Change Biol. 13, 679 (2007).

35. L. M. Mercado et al., Nature 458, 1014 (2009).

36. R. H. Whittaker, G. E. Likens, Primary Productivity of the Biosphere, H. Lieth, R. H. Whittaker, Eds. (Springer-Verlag, Berlin, 1975), pp. 305-328.

37. R. R. Nemani et al., Science 300, 1560 (2003).

38. D. Gerten et al., Geophys. Res. Lett. 32, L21408 (2005).

39. G. Meehl et al., in Climate Change 2007: The Physical Science Basis. Contribution of Working Group I to the Fourth Assessment Report of the Intergovernmental Panel on Climate Change, S. Solomon et al., Eds. (Cambridge University Press, Cambridge and New York, 2007), pp. 747-845.

40. This work used eddy covariance data acquired by the FLUXNET community and in particular by the following networks: Ameriflux [U.S. Department of Energy, Biological and Environmental Research, Terrestrial Carbon Program (DEFG02-04ER63917 and DE-FG02-04ER63911)], AfriFlux, AsiaFlux, CarboAfrica, CarboEuropelP, Carboltaly, CarboMont, ChinaFlux, Fluxnet-Canada (supported by CFCAS, NSERC, BIOCAP, Environment Canada, and NRCan), GreenGrass, KoFlux, LBA, NECC, OzFlux, TCOS-Siberia, and USCCC. We acknowledge the support to the eddy covariance data harmonization provided by CarboEuropeIP, FAO-GTOS-TCO, Integrated Land Ecosystem-Atmosphere Processes Study, Max
Planck Institute for Biogeochemistry, National Science Foundation, University of Tuscia, Université Laval and Environment Canada and U.S. Department of Energy and the database development and technical support from Berkeley Water Center, Lawrence Berkeley National Laboratory, Microsoft Research eScience, Oak Ridge National Laboratory, University of California-Berkeley, and University of Virginia. Remotely sensed land cover, fAPAR, and LAI were available through the Joint Research Centre of the European Commission, the National Aeronautics and Space Administration, and the projects GLC2000 and CYCLOPES. Climate data came from the European Centre for MediumRange Weather Forecasts, the Climate Research Unit of the University of East Anglia, and the GEWEX project GPCP. We thank Mahendra K. Karki at GMAO/NASA for extracting the MOD17 required surface meteorological variables from the GMAO reanalysis dataset and Maosheng Zhao at NTSG of University of Montana for calculating the respective daytime VPD. We further acknowledge support by the European Commission FP7 projects COMBINE and CARBO-Extreme and a grant from the Max-Planck Society establishing the MPRG Biogeochemical Model-Data Integration. C.B., D.P., M.R., P.C., D.B., and S.L. conceived the study. C.B., C.R., D.P., E.T., M.]., M.R., and N.C. contributed diagnostic modeling results. C.B., A.B., G.B.B., M.L., F.I.W., and N.V. contributed process model results. C.B., E.T., and M.R. performed the analysis. C.B. and M.R. wrote the manuscript. All other coauthors contributed with data or substantial input to the manuscript.

\section{Supporting Online Material}

www.sciencemag.org/cgi/content/full/science.1184984/DC1 Materials and Methods

SOM Text

Figs. S1 to S34

Tables S1 to S9

References

20 November 2009; accepted 8 June 2010

Published online 5 July 2010;

10.1126/science.1184984

Include this information when citing this paper.

\section{Global Convergence in the}

\section{Temperature Sensitivity of Respiration at Ecosystem Level}

Miguel D. Mahecha, ${ }^{1,2 *}$ Markus Reichstein, ${ }^{1}$ Nuno Carvalhais, ${ }^{1,3}$ Gitta Lasslop, ${ }^{1}$ Holger Lange, ${ }^{4}$ Sonia I. Seneviratne, ${ }^{2}$ Rodrigo Vargas, ${ }^{5}$ Christof Ammann, ${ }^{6}$ M. Altaf Arain, ${ }^{7}$ Alessandro Cescatti, ${ }^{8}$ Ivan A. Janssens, ${ }^{9}$ Mirco Migliavacca, ${ }^{10}$ Leonardo Montagnani, ${ }^{11,12}$ Andrew D. Richardson ${ }^{13}$

The respiratory release of carbon dioxide $\left(\mathrm{CO}_{2}\right)$ from the land surface is a major flux in the global carbon cycle, antipodal to photosynthetic $\mathrm{CO}_{2}$ uptake. Understanding the sensitivity of respiratory processes to temperature is central for quantifying the climate-carbon cycle feedback. We approximated the sensitivity of terrestrial ecosystem respiration to air temperature $\left(Q_{10}\right)$ across 60 FLUXNET sites with the use of a methodology that circumvents confounding effects. Contrary to previous findings, our results suggest that $Q_{10}$ is independent of mean annual temperature, does not differ among biomes, and is confined to values around $1.4 \pm 0.1$. The strong relation between photosynthesis and respiration, by contrast, is highly variable among sites. The results may partly explain a less pronounced climate-carbon cycle feedback than suggested by current carbon cycle climate models.

$\mathrm{Q}$ uantifying the intensity of feedback mechanisms between terrestrial ecosystems and climate is a central challenge for understanding the global carbon cycle and a prerequisite for reliable future climate scenarios $(1,2)$. One crucial determinant of the climate-carbon cycle feedback is the temperature sensitivity of respiratory processes in terrestrial ecosystems $(3,4)$, which has been subject to much debate (5-10). On the one hand, empirical studies have found high sensitivities of soil respiration to temperature, with values of $Q_{10}$ (here an indicator of the sensitivity of terrestrial ecosystem respiration to air temperature) well above $2(11,12)$. Dependencies of $Q_{10}$ values on mean temperatures $(12,13)$ have been attributed to the acclimatization of soil respiration (5), among other factors (13). On the other hand, global-scale models often make use of globally constant $Q_{10}$ values of 2 or below to generate carbon dynamics consistent with global atmospheric $\mathrm{CO}_{2}$ growth rates $(3,14,15)$. Nonetheless, several models have directly included empirical dependencies of the parameterization of respiratory processes to environmental dynamics (16-18). This inclusion is questionable, given that single-site studies have indicated that factors seasonally covarying with temperature can confound the experimental retrieval

${ }^{1}$ Max Planck Institute for Biogeochemistry, 07745 Jena, Germany. ${ }^{2}$ Institute for Atmospheric and Climate Science, ETH Zürich, Universitätsstrasse 16, 8092 Zürich, Switzerland. ${ }^{3}$ Faculdade de Ciências e Tecnologia, FCT, Universidade Nova de Lisboa, 2829-516 Caparica, Portugal. ${ }^{4}$ Norsk Institutt for Skog og Landskap, N-1431 Ås, Norway. ${ }^{5}$ Department of Environmental Science, Policy and Management, University of California, Berkeley, CA 94720, USA. ${ }^{6}$ Agroscope ART, Federal Research Station, Reckenholzstr. 191, CH-8046 Zürich, Switzerland. ${ }^{7}$ McMaster Centre for Climate Change, McMaster University, Hamilton, Ontario L8S 4L8, Canada. ${ }^{8}$ European Commission, Joint Research Center, Institute for Environment and Sustainability, I-21027 Ispra, Italy. 'Department of Biology, University of Antwerpen, Universiteitsplein 1, 2610 Wilrijk, Belgium. ${ }^{10}$ Remote Sensing of Environmental Dynamics Laboratory, DISAT, University of Milano-Bicocca, 20126 Milano, Italy. ${ }^{11}$ Servizi Forestali, Agenzia per l'Ambiente, Provincia Autonoma di Bolzano, 39100 Bolzano, Italy. ${ }^{12}$ Faculty of Sciences and Technologies, Free University of Bozen-Bolzano, Piazza Università 1, 39100 Bolzano, Italy. ${ }^{13}$ Harvard University Department of Organismic and Evolutionary Biology, Harvard University Herbaria, 22 Divinity Avenue, Cambridge, MA 02138, USA.

*To whom correspondence should be addressed. E-mail: mmahecha@bgc-jena.mpg.de 


\section{Science}

\section{Terrestrial Gross Carbon Dioxide Uptake: Global Distribution and Covariation with Climate}

Christian Beer, Markus Reichstein, Enrico Tomelleri, Philippe Ciais, Martin Jung, Nuno Carvalhais, Christian Rödenbeck, M. Altaf Arain, Dennis Baldocchi, Gordon B. Bonan, Alberte Bondeau, Alessandro Cescatti, Gitta Lasslop, Anders Lindroth, Mark Lomas, Sebastiaan Luyssaert, Hank Margolis, Keith W. Oleson, Olivier Roupsard, Elmar Veenendaal, Nicolas Viovy, Christopher Williams, F. lan Woodward and Dario Papale

Science 329 (5993), 834-838.

DOI: 10.1126/science.1184984originally published online July 5, 2010

\section{Carbon Cycle and Climate Change}

As climate change accelerates, it is important to know the likely impact of climate change on the carbon cycle (see the Perspective by Reich). Gross primary production (GPP) is a measure of the amount of $\mathrm{CO}_{2}$ removed from the atmosphere every year to fuel photosynthesis. Beer et al. (p. 834, published online 5 July) used a combination of observation and calculation to estimate that the total GPP by terrestrial plants is around 122 billion tons per year; in comparison, burning fossil fuels emits about 7 billion tons annually. Thirty-two percent of this uptake occurs in tropical forests, and precipitation controls carbon uptake in more than $40 \%$ of vegetated land. The temperature sensitivity (Q10) of ecosystem respiratory processes is a key determinant of the interaction between climate and the carbon cycle. Mahecha et al. (p. 838, published online 5 July) now show that the Q10 of ecosystem respiration is invariant with respect to mean annual temperature, independent of the analyzed ecosystem type, with a global mean value for Q10 of 1.6 . This level of temperature sensitivity suggests a less-pronounced climate sensitivity of the carbon cycle than assumed by recent climate models.

ARTICLE TOOLS

SUPPLEMENTARY MATERIALS

RELATED
CONTENT

REFERENCES

PERMISSIONS http://science.sciencemag.org/content/329/5993/834

http://science.sciencemag.org/content/suppl/2010/07/01/science.1184984.DC1 http://science.sciencemag.org/content/sci/330/6010/1476.3.full

http://science.sciencemag.org/content/sci/329/5993/774.full http://science.sciencemag.org/content/sci/329/5993/838.full file:/contentpending:yes

This article cites 30 articles, 4 of which you can access for free http://science.sciencemag.org/content/329/5993/834\#BIBL

http://www.sciencemag.org/help/reprints-and-permissions

Use of this article is subject to the Terms of Service

Science (print ISSN 0036-8075; online ISSN 1095-9203) is published by the American Association for the Advancement of Science, 1200 New York Avenue NW, Washington, DC 20005. The title Science is a registered trademark of AAAS.

Copyright @ 2010, American Association for the Advancement of Science 